\title{
Predation of freshwater jellyfish on Bosmina: the consequences for population dynamics, body size, and morphology
}

\author{
Thomas Jankowski ${ }^{1,2}$ \\ ${ }^{1}$ Department of Biology V, Aachen University, Worringer Weg 1, D-52056 Aachen, Germany \\ ${ }^{2}$ Present address: EAWAG, $W \& T$, Ueberlandstrasse 133, CH-8600 Duebendorf, Switzerland \\ (E-mail: Thomas.Jankowski@uni-konstanz.de)
}

Key words: Craspedacusta, Hydrozoa, Cladocera, morphological defense, enclosure experiment

\begin{abstract}
Invertebrate predators may cause strong changes in behaviour, life-history, and morphology of prey species. However, little is known about the influence of jellyfish on such characteristics of their prey. This study analyses the impacts of the freshwater jellyfish Craspedacusta sowerbii on life history and morphological defenses in a population of the cladoceran Bosmina longirostris. Length of mucro and antennule, sizedependent number of eggs, size at maturity, and size of juveniles, adults, and egg-carrying females were investigated during a 23 days experiment using medusae-enriched and control enclosures filled with natural plankton populations. Significant differences in parameters investigated were found not only between treatments, but also within treatments over time. Changes in Bosmina life-history parameters and morphology in controls were probably due to predation by cyclopoid copepods. The significant increase in the size of adults and egg-carrying females as well as the increase in mucro and antennule length in medusaeenriched enclosures are discussed as defense strategies against the freshwater jellyfish.
\end{abstract}

\section{Introduction}

Predation can have a strong impact on prey communities by influencing the evolution of defense strategies in the prey (Agrawal et al., 1999). Because in plankton communities, the environment offers few refugia for avoiding predators, prey have evolved adaptations to reduce predation risk. The presence of predators can induce life-history (Crowl \& Covich, 1990), behavioural (Stich \& Lampert, 1981), and morphological (Stemberger \& Gilbert, 1987; Boersma et al., 1998) changes in zooplankton species. Many such traits develop only in the presence of predators. For example, selectivity for larger zooplankton and induction of diel vertical migration is well documented for fish (Brooks \& Dodson, 1965; Stich \& Lampert, 1981). Smaller zooplankton, in contrast, may be more vulnerable to invertebrate predators. Therefore, allocation of more energy to body growth (Chase, 1999) and lengthening of body appendages such as helmets and neckspines of Daphnia can be effective against invertebrate predators (Repka et al., 1995; Sell, 2000) because those like Leptodora, Chaoborus, and predatory copepods, which have to hold and manipulate prey items after capture, might be affected by bulky appendages of their prey.

In this study, the predatory influence of the freshwater jellyfish Craspedacusta sowerbii Lankester, 1880, on life-history and morphological traits of the small cladoceran Bosmina longirostris O.F. Müller, 1785, was investigated. Bosmina shows a variety of phenotypes, with many species exhibiting large differences in body size, shape, and length of appendages (Lieder, 1996). Field observations (Kerfoot, 1977; Sprules et al., 1984) as well as laboratory experiments (Kerfoot, 1987) on bosminids suggest that these characteristics are 
influenced by the presence of predators. In lakes with high invertebrate predation pressure, small bosminids tend to have longer appendages for a given body size than they do in lakes with few predators; large, less vulnerable bosminids do not show this pattern. As shown experimentally, large omnivorous calanoid copepods can be indirectly responsible for significant increases in mucro and antennule lengths and egg size (Kerfoot, 1977, 1987). This allocation to defense may be energetically balanced by fewer eggs (Kerfoot, 1977). Additionally, juveniles tend to allocate energy to somatic growth to achieve a size refuge from predation. Recent studies demonstrated that bosminids with extreme morphological traits might be less vulnerable to predation by Leptodora (Hellsten et al., 1999) and small cyclopoid copepods like Mesocyclops (Chang \& Hanazato, 2003).

Little is known about the influence of freshwater jellyfish on life-history and morphological characters of zooplankton (Purcell, 1997), although there is increasing evidence that jellyfish can significantly influence zooplankton abundance and community structure, with cascading trophic effects (Purcell, 1997). For example, in a long-term enclosure experiment, Craspedacusta significantly reduced densities of crustacean plankton, which indirectly boosted phytoplankton blooms (Jankowski \& Ratte, 2001). During this study some evidence for differences in life-history traits and appendage lengths was obtained. Data from this enclosure experiment were re-analysed to investigate the following question: Do populations of $B$. longirostris respond to $C$. sowerbii by (1) being larger at maturity, (2) allocating more energy to somatic growth and less to egg production at smaller-sized stages, and/or (3) increasing mucro and antennule lengths?

\section{Methods}

Study site

Lake Alsdorf is a eutrophic (mean $P_{\text {total }}$ $=0.124 \mathrm{mg} \mathrm{l}^{-1}$ ) pond near Aachen, Germany, with a surface area of 3.1 ha, a mean depth of 2.6 $\mathrm{m}$, and a maximum depth of $4.1 \mathrm{~m}$. Protection from wind causes a stable thermal stratification with an anoxic hypolimnion that persists through the summer (Strauss \& Ratte, 2002). Roach (Rutilus rutilus) dominates the fish community, accounting for $80 \%$ of fish by numbers. The total fish biomass was estimated, by electrofishing and echosounding in 1997, as ca. $350 \mathrm{~kg} \mathrm{ha}^{-1}$ (Strauss \& Ratte, 2002). Due to the heavy predation by roach and perch, the zooplankton is dominated by small bosminids, cyclopoid copepods, and rotifers. In 1995 and 1996, a bloom of the freshwater jellyfish Craspedacusta sowerbii was observed with up to 1000 individuals $\mathrm{m}^{-2}$.

\section{Enclosure experiment}

A 23 days enclosure experiment was carried out from mid-June to July 1996. Six enclosures (100 $\mu \mathrm{m}$ polyethylene/polyamide sheeting, $2 \mathrm{~m}$ long, $1 \mathrm{~m}$ diameter, 1800 1) were filled with $800 \mu \mathrm{m}$ filtered lake water to exclude medusae and fish (controls). Three of these enclosures were enriched with jellyfish at 800 individuals per enclosure, reflecting the 1995 abundance of nearly 1000 individuals $\mathrm{m}^{-2}$. On each sampling day, temperature was measured, and samples were taken at 0,1 , and $2 \mathrm{~m}$ depth with a 'Ruttner' water sampler and mixed.

This mixed sample was subsampled to measure chlorophyll $a$ and phyto- and zoo-plankton (Jankowski \& Ratte, 2001). For zooplankton, three subsamples of 11 each were filtered through a 50$\mu \mathrm{m}$ sieve and preserved in $70 \%$ ethanol. Each subsample was counted using an inverted microscope at $50 \times$. Life-history parameters of the experimental bosminid populations were investigated using the first 50 females of each subsample. Both body length and egg number of a total of 3199 individuals were determined. To estimate abundance of adult and juvenile females and size at maturity (SAM), the smallest egg-carrying female of each enclosure on each sampling day was determined. Females smaller than the smallest eggcarrying female were considered to be juveniles, whereas larger females were designated as adults. Differences in the time course of the investigated parameters were analysed using repeated measures analysis of variance (SAS Institute, 1988). Length of mucro and antennule were measured in around 50 individuals at the beginning and the end of the experiment for each enclosure. 


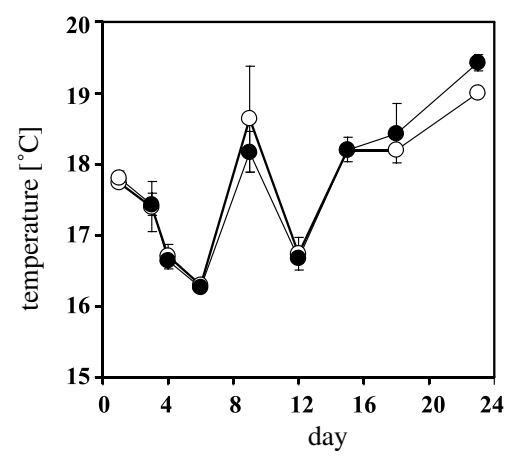

Figure 1. Time course of temperatures (mean \pm SE) in medusae-enriched (black) and control (white) enclosures.

\section{Results}

Temperatures in the enclosures, ranging from 16 to $19^{\circ} \mathrm{C}$, were not different between treatments (Fig. 1). Copepod dynamics differed markedly between treatments (Fig. 2): in controls, the abundance of copepodids and adult copepods was $12-80$ and $1-20$ individuals $1^{-1}$, respectively, whereas in medusae-enriched enclosures copepodid abundances ranged between 1 and 12 individuals $1^{-1}$, and adult copepods never exceeds one individual $1^{-1}$.

At the beginning of the experiment, none of the bosminid life-history or morphological parameters under investigation showed significant differences between populations in medusae-enriched and control enclosures. Abundance of adult and juvenile females decreased slowly and continuously in the medusae treatment. In contrast, control populations were significantly more dense by the end of the experiment, as indicated by the significant day $\times$ treatment interaction for juveniles
$\left(F_{5,20}=4.38, p=0.0075\right)$ and significant treatment differences $\left(F_{1,20}=7.83, p=0.048\right)$ for adults (Fig. $3)$. These differences were caused by significantly higher mortality and greater absolute egg production in control enclosures (day $\times$ treatment interaction, $\left.F_{5,20}=8.19, p=0.0002\right)$. Population size decreased in medusae enclosures even though egg production increased. However, egg production per female was relatively low, being no more than three. Egg production per adult female was slightly, but not significantly, higher in the medusae enclosures compared to controls.

Time course of SAM differed significantly between controls and medusae-enriched enclosures $\left(F_{5,20}=38.66, p=0.0034\right)$. In control enclosures, mean SAM increased from around $0.225 \mathrm{~mm}$ at the beginning of the experiment to $>0.275 \mathrm{~mm}$, whereas in the medusae enclosures, mean SAM did not change appreciably from beginning to end of the experiment (Fig. 3). Size of egg-carrying females $\quad\left(F_{5,20}=20.42, \quad p<0.0001\right), \quad$ adults $\left(F_{5,20}=12.20, \quad p<0.0001\right), \quad$ and juveniles $\left(F_{5,20}=4.40, p<0.0073\right)$ all varied significantly during the experiment and were larger in controls (Fig. 3). Whereas juveniles stayed around $0.2 \mathrm{~mm}$ in the medusae enclosures, they grew to $0.25 \mathrm{~mm}$ in controls. The average size of adult females and egg-carrying females increased in control and medusae enclosures, but effects were more pronounced in controls. The mean size of egg-carrying females rose $40 \%$ in controls but only $20 \%$ in medusae enclosures. On average, adult females increased about $0.1 \mathrm{~mm}$ in controls and around $0.025 \mathrm{~mm}$ in medusae treatments.

Size-dependent egg production differed strongly between medusae-enriched and control
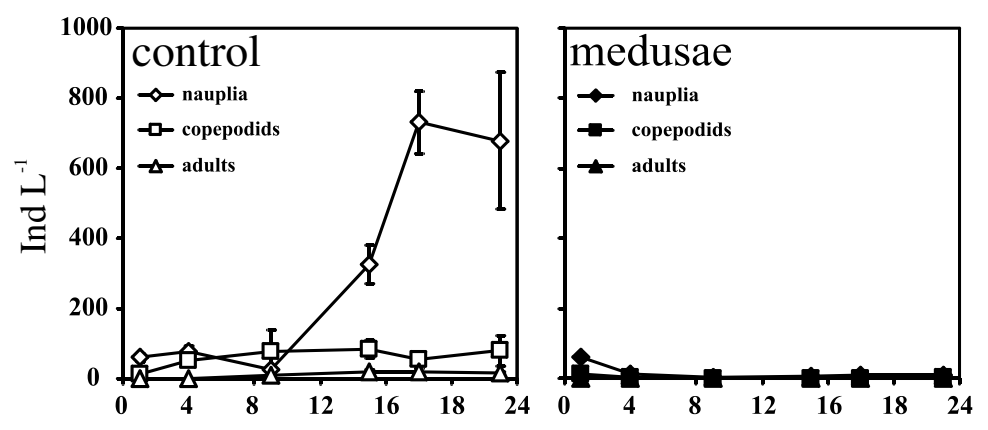

Figure 2. Time course of abundance dynamics of copepod stages (mean \pm SE) in medusae-enriched (right) and control (left) enclosures. Ind, number of individuals. 

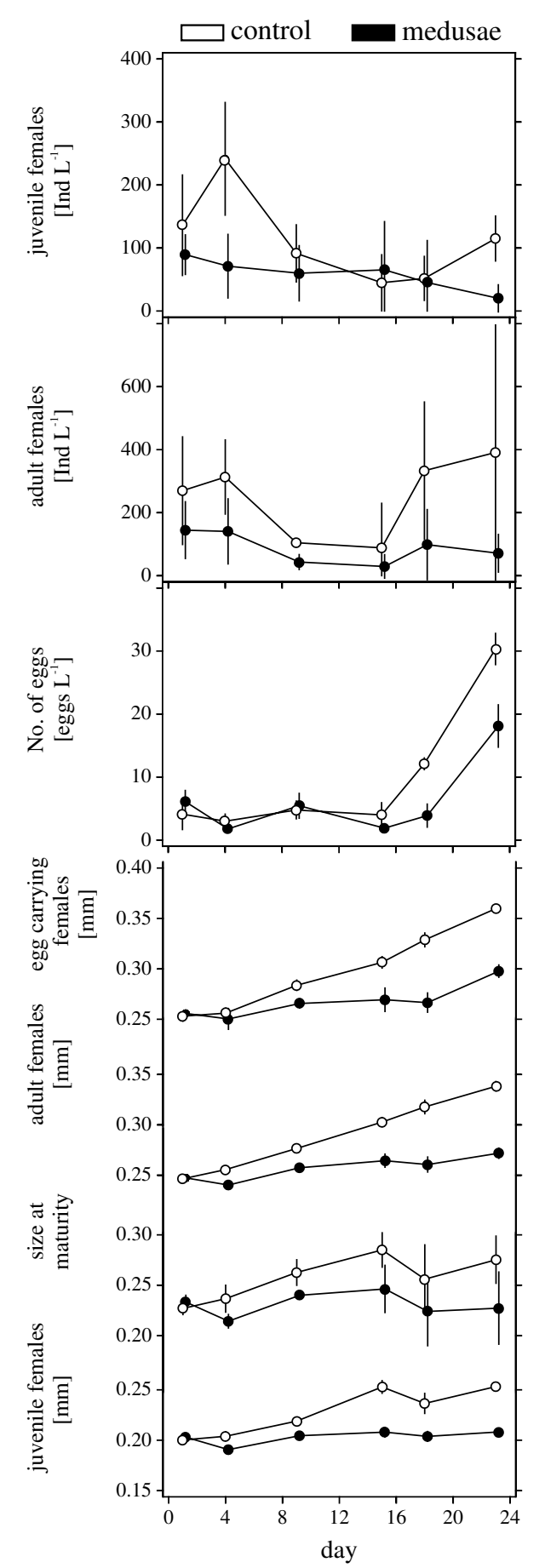

Figure 3. Time course of the population dynamics, life-history characteristics, and body size of several stages of the B. longirostris population in medusae-enriched (black) and control (white) enclosures. Shown are mean $\pm \mathrm{SE}$ of three replicates. From top: abundance of juvenile females, abundance of adult females, abundance of parthenogenetic eggs, size of egg-carrying females, size of adult females, size at maturity, and size of juvenile females. Ind, number of individuals. enclosures (Fig. 4). In particular, small adult females, between 0.25 and $0.35 \mathrm{~mm}$, produced significantly more eggs in medusae enclosures than in controls $\left(\mathrm{F}_{1,55}=19.31, p=<0.0001\right)$, including body size as a co-variable. Bosminids in medusae enclosures had not only a smaller SAM but also produced more eggs.

At the beginning of the experiment there were no differences in mucro or antennule length between medusae and control enclosures (Figs 5-7). Initial mucro length, which ranged from 2 to $28 \mu \mathrm{m}$, increased over the experiment in both treatments to $<56 \mu \mathrm{m}$. When body size is included as a co-variable, mucro length increased significantly in both treatments over time and was significantly higher in controls $\left(F_{3,172}=14.68\right.$, $p<0.0001)$. Additionally, body size $\left(F_{1,172}=\right.$ 88.96, $p<0.0001)$ and body size $\times$ treatment interaction $\left(F_{3,172}=6.90, p=0.0002\right)$ had a significant effect on mucro length, the increase in mucro length being greater in large, adult females in control enclosures $(156 \%$, Fig. 7$)$ than in medusae enclosures, in which it also increased $(66 \%)$. Juvenile females showed a different pattern: significant differences were found only in the controls at the end of the study, with an increase from 13.0 to $29.9 \mu \mathrm{m}(130 \%)$. Nearly the same pattern was observed for antennule length (Figs 6 and 7), but the lengthening was not as strong as for the mucro: it increased from 43 to $91 \mu \mathrm{m}$ at the beginning to up to $163 \mu \mathrm{m}$ at the end. Antennule lengths were not significantly different between medusae and control enclosures at the start, but

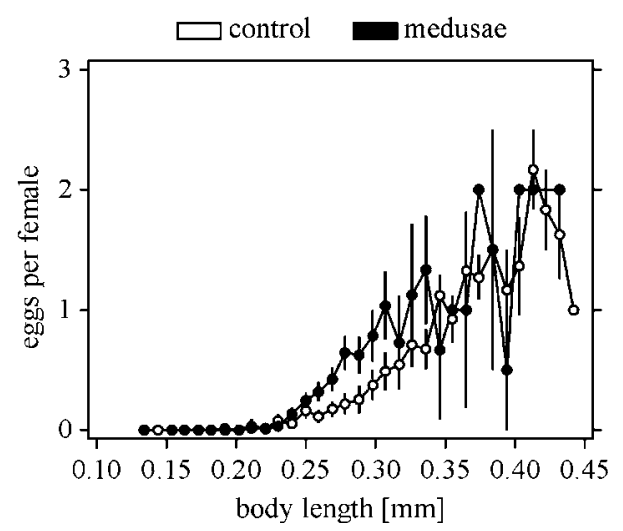

Figure 4. Differences in the average number of eggs per female of $B$. longirostris in relation to body length in medusae (black) and control (white) enclosures (mean $\pm \mathrm{SE}$ ). 


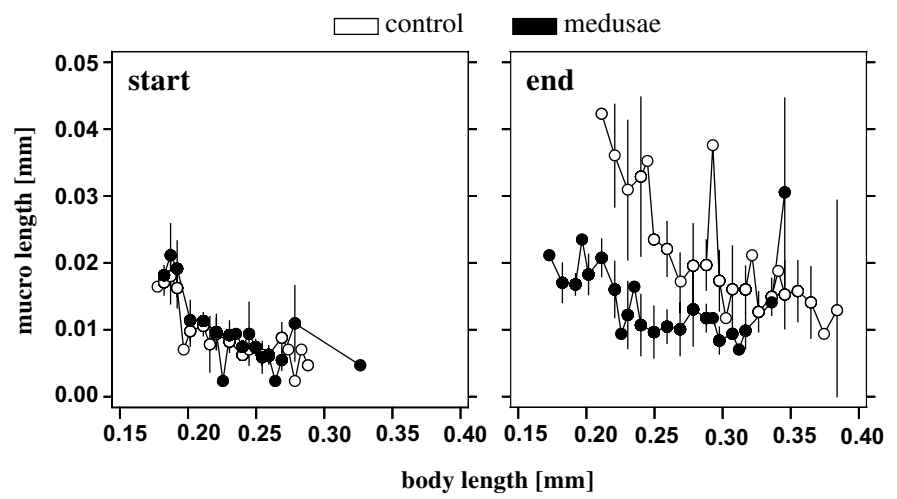

Figure 5. Differences in mucro length in relation to body length of the B. longirostris populations in medusae (black) and control (white) treatments (mean $\pm \mathrm{SE}$ ) at the beginning (left) and end (right) of the experiment.

were significantly longer in controls at the end. Moreover, values of antennule length for all enclosures were significantly larger at the end of the study $\left(F_{3,176}=265.81, p<0.0001\right.$, Fig. 7$)$. Antennule length of adult females increased around $79 \%$ in controls and $\sim 14 \%$ in medusae enclosures, respectively. Juveniles showed no increase in antennule length within medusae enclosures, but increased significantly in controls (from 65 to $134 \mu \mathrm{m}, 106 \%$ ).

\section{Discussion}

In the enclosure experiment, there were not only significant differences in bosminid population dynamics, but also in life-history and morphological parameters. Bosminid populations in medusae enclosures showed a significantly smaller SAM and, consequently, a smaller size of juveniles, adults, and egg-carrying females. Additionally, the smaller adults produced more eggs than similar sized adults in controls. In medusae as well as control enclosures, adults developed longer mucros and antennules during the experiment, although it was more pronounced in the controls. For juveniles, a significant increase in mucro and antennule lengths was observed only in controls.

As reported elsewhere (Jankowski \& Ratte, 2001), predation by Craspedacusta sowerbii caused significantly lower abundances of bosminids and cyclopoid copepods compared to control enclosures; indeed, adult cyclopoid copepods were absent in the medusae treatment. Cyclopoid copepods in medusae-free enclosures were dominated by small species, e.g. Mesocyclops sp. and

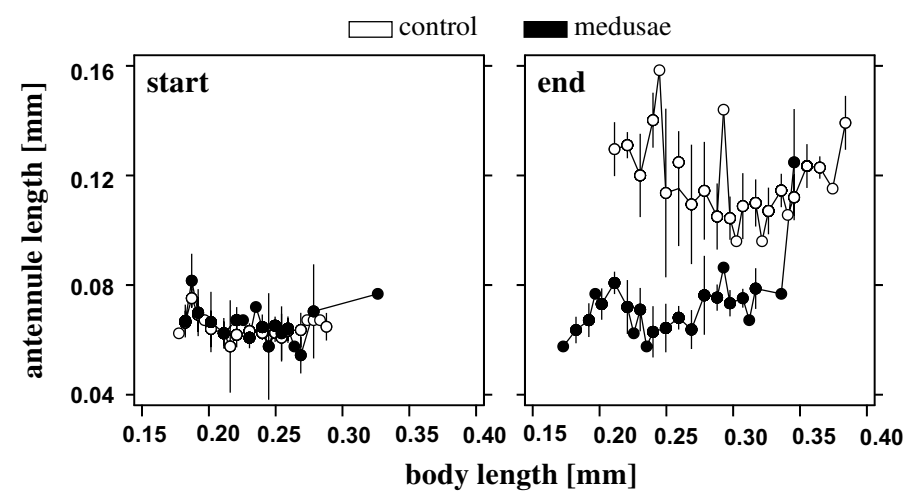

Figure 6. Differences in antennule length in relation to body length of the B. longirostris populations in medusae (black) and control (white) treatments (mean $\pm \mathrm{SE}$ ) at the beginning (left) and end (right) of the experiment. 

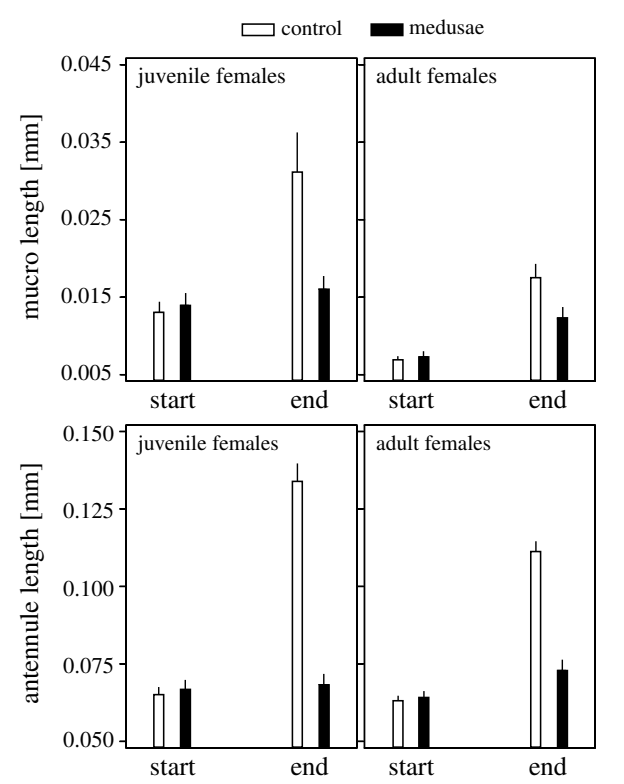

Figure 7. Mean \pm SE of mucro (top) and antennule (bottom) length of juvenile (left) and adult (right) bosminids at the beginning and end of the experiment.

Thermocyclops sp. Larger species, e.g. Marcocyclops sp. and Cyclops sp., also occurred but at very low abundances. Additionally, Craspedacusta caused cascading effects: the lower grazing pressure by bosminids caused significantly higher chlorophyll- $a$ concentrations in the medusae-enriched enclosures.

In control enclosures, where copepods reached high abundances, Bosmina longirostris reacted typically to predation by copepods (Kerfoot, 1987; Kappes \& Sinsch, 2002; Chang \& Hanazato, 2003): the population showed an increase in body size as well as mucro and antennule length. Additionally, this study strongly suggests that (1) the size at maturity increased, and (2) more energy was allocated to somatic growth than to early reproduction, thereby achieving a size refuge from predation. Hence, these differences between control and medusae enclosures were probably not caused directly by the presence or absence of Craspedacusta, but instead were the indirect result of predation by these jellyfish on copepods. The fact that small cyclopoid copepods, e.g., Mesocyclops sp., can influence the B. longirostris population is a relatively new idea (Kappes \& Sinsch, 2002; Chang \& Hanazato, 2003), because these small predators are primarily known as rotifer predators (Gilbert \& Williamson, 1978; Williamson, 1980, 1983, 1984). In contrast, large copepods, like Epischura sp. and Cyclops sp., are already known to cause life-history and morphological changes in small cladoceran species (Kerfoot, 1980, 1987). Life-history plasticity of prey organisms can strongly influence the outcome of food web interactions (Chase, 1999).

In medusae enclosures there was nearly no change in size at maturity (and hence the size of juveniles), suggesting that Craspedacusta did not influence the life history of $B$. longirostris. This is supported by the relatively high number of eggs carried by small females. These two facts in combination suggest that these cladocerans have no need to invest in higher somatic growth to reach a size refuge, where predation risk is lower. In contrast, the size differences of adult and egg-carrying females between treatments suggests that $C$. sowerbii showed size-selective predation, jellyfish selecting larger individuals of bosminids. This is in agreement with other studies showing that prey capture increases with prey size (reviewed in Purcell, 1997), as long as escape velocities of prey are not the limiting factor (as in adult copepods). However, size selection of $C$. sowerbii seems not to be as strong as size selection by fish (Brooks \& Dodson, 1965). As the enclosures were filled with natural plankton and the predation pressure by roach is pronounced in this lake (Strauss \& Ratte, 2002), the increase in body size of adult females was probably caused by the absence of fish predation in the enclosures.

Although elongation of mucro and antennule during the experiment was much greater in the controls, a significant increase was also observed in the medusae treatment. In contrast to the controls, this elongation was observed only for larger females. Morphological defense appendages are costly and investment in them reduces fecundity (Kerfoot, 1977), probably because extreme morphotypes need more energy for swimming (Lagergren et al., 1997). Hence, investment in defensive appendages in the medusae treatment was not coincidental. It is surprising that increased appendage length was observed in larger females: studies of other invertebrate predators (e.g., copepods, Chaoborus sp., and Leptodora sp.) have shown predation risk to be more pronounced for juveniles, so prey juveniles often show a stronger 
response to these predators than do adults (Kerfoot, 1987). Adult copepods and other invertebrate predators except $C$. sowerbii were absent in the medusae enclosures, and densities of copepodids, which feed on phytoplankton and rotifers (Gilbert \& Williamson, 1978; Williamson, 1980, 1983, 1984; Hansen \& Santer, 1995), were $<2$ individuals $1^{-1}$ except at the start of the experiment. Hence, predators other than $C$. sowerbii could not be the reason for the observed induction of defense appendages in bosminids. In addition to predators, abiotic factors can trigger modifications in cladoceran morphology (Hanazato \& Dodson, 1995; Kappes \& Sinsch, 2002), but abiotic conditions such as temperature were nearly constant during the experiment (Jankowski, unpublished data).

What caused the large bosminids to invest in costly appendages? The most likely explanation is the presence of $C$. sowerbii. While there is evidence that elongation of appendages in bosminids increases handling time of them by predators and opportunities for their escape if caught by predators like Leptodora (Hellsten et al., 1999), this does not appear to apply to predation by Craspedacusta, which has a different hunting behaviour. Craspedacusta floats while feeding from the surface to deeper parts. During this time, the tentacles are exposed like a filter; thus water flow brings prey toward the tentacles. In marine medusae, prey species vulnerability varies with the predator's nematocyst types (Purcell \& Mills, 1988) and the number and spacing of tentacles (Purcell, 1997). In consideration of this hunting behaviour, there seems to be no need for adult bosminids to produce costly appendages to reduce the handling time for medusae.

In conclusion, this study showed that Craspedacusta induced no direct life-history changes in $B$. longirostris, but induced morphological defenses like lengthening mucro and antennule. Further investigation is needed to resolve the mechanisms that were involved.

\section{Acknowledgments}

I thank Peter Schmidt (Aachen) and Hans-Toni Ratte (Aachen) for their supervision of this research and Tido Strauss for his field work support and fruitful discussions. Local fishermen gener- ously provided admission for the enclosure experiment and the field survey. I thank Dietmar Straile for providing space and time to continue the work on Craspedacusta. Part of the work was funded by the council of the city of Alsdorf. Manuscript preparation would have been impossible without the German welfare system. The manuscript was greatly improved by the comments and suggestions of the two reviewers. I also thank Daphne Fautin for organization of the ICCB7 and preparation of these proceedings, and the German Science Foundation (DFG) for the travel grant.

\section{References}

Agrawal, A. A., C. Laforsch \& R. Tollrian, 1999. Transgenerational induction of defences in animals and plants. Nature 401: 60-63.

Boersma, M., P. Spaak \& L. DeMeester, 1998. Predator-mediated plasticity in morphology, life history, and behavior of Daphnia: the uncoupling of responses. American Naturalist 152: 237-248.

Brooks, J. L. \& S. I. Dodson, 1965. Predation, body size, and composition of plankton. Science 150: 28-35.

Chang, K.-H. \& T. Hanazato, 2003. Vulnerability of cladoceran species to predation by the copepod Mesocyclops leuckarti: laboratory observations on the behavioural interactions between predator and prey. Freshwater Biology 48: 476-484.

Chase, J. M., 1999. To grow or to reproduce? The role of lifehistory plasticity in food web dynamics. American Naturalist 154: 571-586.

Crowl, T. A. \& A. P. Covich, 1990. Predator-induced life-history shifts in a freshwater snail. Science 247: 949-951.

Gilbert, J. J. \& C. E. Williamson, 1978. Predator-prey behavior and its effect on rotifer survival in associations of Mesocyclops edax, Asplanchna girodi, Polyarthra vulgaris, and Keratella cochlearis. Oecologia 37: 13-22.

Hanazato, T. \& S. I. Dodson, 1995. Synergistic effects of low oxygen concentration, predator kairomone, and a pesticide on the cladoceran Daphnia pulex. Limnology and Oceanography 40: 700-709.

Hansen, A.-M. \& B. Santer, 1995. The influence of food resources on the development, survival and reproduction of two cyclopoid copepods: Cyclops vicinus and Mesocyclops leuckarti. Journal of Plankton Research 17: 631-646.

Hellsten, M., R. Lagergren, \& J. Stenson, 1999. Can extreme morphology in Bosmina reduce predation risk from Leptodora? An experimental test. Oecologia 118: 23-28.

Jankowski, T. \& H. T. Ratte, 2001. On the influence of the freshwater jellyfish Craspedacusta sowerbii on the zooplankton community. Verhandlungen der Internationalen Vereinigung für Theoretische und Angewandte Limnologie 27: 3287-3290.

Kappes, H. \& U. Sinsch, 2002. Temperature- and predatorinduced phenotypic plasticity in Bosmina cornuta and 
B. pellucida (Crustacea: Cladocera). Freshwater Biology 47: 1944-1955.

Kerfoot, W. C., 1977. Competition in cladoceran communities: the cost of evolving defenses against copepod predation. Ecology 58: 303-313.

Kerfoot, W. C., 1980. Predatory copepods and Bosmina: replacement cycles and further influences of predation upon prey reproduction. Ecology 61: 417-431.

Kerfoot, W. C., 1987. Translocation experiments: Bosmina responses to copepod predation. Ecology 68: 596-610.

Lagergren, R., M. Hellstein \& J. A. E. Stenson, 1997. Increased drag, and thus lower speed: a cost for morphological defence in Bosmina (Eubosmina) (Crustacea: Cladocera). Functional Ecology 11: 484-488.

Lieder, U., 1996. Crustacea: Cladocera/Bosminidae. Gustav Fischer Verlag, Stuttgart.

Purcell, J. E., 1997. Pelagic cnidarians and ctenophores as predators: selective predation, feeding rates, and effects on prey populations. Annales de l'Institut Océanographique 73: 125-137.

Purcell, J. E. \& C. E. Mills, 1988. The correlation between nematocyst types and diets in pelagic hydrozoa. In Hessinger, D. A. \& H. M. Lenhoff (eds), The Biology of Nematocysts. Academic Press, San Diego: 463-485.

Repka, S., M. Walls \& M. Ketola, 1995. Neck spine protects Daphnia pulex from predation by Chaoborus, but individuals with longer tail spine are at greater risk. Journal of Plankton Research 17: 393-403.

SAS Institute, 1988. SAS/STAT User's Guide. Version 6.12. SAS Institute, North Carolina.
Sell, A. F., 2000. Morphological defences induced in situ by the invertebrate predator Chaoborus: comparison of responses between Daphnia pulex and D. rosea. Oecologia 125: 150-160.

Sprules, W. G., J. C. H. Carter \& C. W. Ramcharan, 1984. Phenotypic associations in the Bosminidae (Cladocera): zoogeographic patterns. Limnology and Oceanography 29: 161-169.

Stemberger, R. S. \& J. J. Gilbert, 1987. Defences of planktonic rotifers against predators. In Kerfoot, W. C. \& A. Sih (eds), Predation: Direct and Indirect Impacts on Aquatic Communities. University Press of New England, London: 227239.

Stich, H. B. \& W. Lampert, 1981. Predator evasion as an explanation of diurnal vertical migration by zooplankton. Nature 293: 396-398.

Strauss, T. \& H. T. Ratte, 2002. Modelling the vertical variation of temperature and dissolved oxygen in a shallow, eutrophic pond as a tool for analysis of the internal phosphorus fluxes. Verhandlungen der Internationalen Vereinigung für theoretische und angewandte Limnologie 28: 1508-1511.

Williamson, C. E., 1980. The predatory behavior of Mesocyclops edax: Predator preferences, prey defenses, and starvationinduced changes. Limnology and Oceanography 25: 903909.

Williamson, C. E., 1983. Invertebrate predation on planktonik rotifers. Hydrobiologia 104: 385-396.

Williamson, C. E., 1984. Laboratory and field experiments on the feeding ecology of the cyclopoid copepod, Mesocyclops edax. Freshwater Biology 14: 575-585. 